\title{
AC 2008-2781: CONFRONTED BY STUDENTS: DEALING WITH ANGER, FRUSTRATION AND MORE PLEASANT EMOTIONS IN OFFICE HOURS AND IN CLASS
}

\section{Rebecca Bates, Minnesota State University-Mankato}

Rebecca Anne Bates received the B.S. degree in biomedical engineering from Boston University in 1990, the M.S. degree in electrical engineering from Boston University in 1996 and the Ph.D. degree in electrical engineering from the University of Washington in 2004. She also received the M.T.S. degree from Harvard Divinity School in 1993. She is currently an Associate Professor in the Computer Science department at Minnesota State University, Mankato. Her research interests include speech recognition and understanding as well as engineering education, with an emphasis on student learning and educational methods.

\section{Denise Wilson, University of Washington}

Denise Michelle Wilson (M'89) was born in Chicago, IL, in 1966. She received the B.S. degree in mechanical engineering from Stanford University,Stanford, CA, in 1988 and the M.S. and $\mathrm{Ph} . \mathrm{D}$. degrees in electrical engineering from the Georgia Institute of Technology, Atlanta, in 1989 and 1995, respectively. She is currently an Associate Professor with the Electrical Engineering Department, University of Washington, Seattle, and she was previously with the University of Kentucky, Lexington, in a similar position from 1996 to 1999. She was also with Applied Materials, a semiconductor capital equipment supplier, from 1990 to 1992 . Her research interests are split between technical investment in the development of signal processing architectures, array platforms, and other infrastructures for visual, auditory, and chemical-sensing microsystems and equivalent interest in engineering education, with particular emphasis on affective and metacognitive factors that influence student success in STEM fields. 


\title{
Confronted by Students: Dealing with Anger, Frustration and More Pleasant Emotions in Office Hours and in Class
}

\begin{abstract}
One of the most challenging and unexpected aspects of a new professor's career is dealing with student emotions. Emotions, especially anger and frustration, can have an impact on student success and willingness to stay engaged with course content. Successfully implementing strategies for dealing with student emotions can result in improved academic outcomes. This paper addresses the impact of student emotions and suggests strategies for faculty to use when interacting with students.
\end{abstract}

\section{Introduction}

The impact of student emotions on learning is rarely discussed in faculty preparation workshops. Guidebooks suggest ways to write syllabi, plan lessons and incorporate active learning strategies but rarely present ways to address the emotions that students experience in the course of their academic careers. Thus, dealing with student emotions is often unexpected and definitely challenging for faculty. Most new faculty are unprepared for students who arrive at office hours stewing with anger, roiling in frustration, bogged down with sadness or giddy with excitement. While the latter encounter is easier to address (and less likely to stop a student from accomplishing his or her academic goals), the entire emotional package comes with each and every student and can have an impact on student success. This effect is especially obvious in engineering and computer science, where students are asked to be at the edge of their learning capacity and rarely spend significant "musing" time on newly acquired information before needing to move on to digesting the next topic.

It is helpful for all faculty to be aware of the effects of the student's emotional fabric as he/she moves through the program, although women faculty often experience student emotions more frequently via connections with both male and female students. Being prepared for confrontations and developing abilities to recognize and defuse situations to insure productive learning experiences will help set up a successful faculty career. As important, faculty need to have in place appropriate scaffolding and support to sustain the transfer of negative emotions that students often, unwittingly, place on faculty.

This paper addresses the issue of student emotions and how they can affect student-faculty rapport and subsequently, academic outcomes including grades, team performance and cognitive/intellectual growth. We focus on viable strategies for faculty to acknowledge and address student emotions while remaining within their capacity to do so.

\section{Background}

Unlike many other fields of research in education, little effort has been directed at understanding affective experience and its impact on engineering education; for example, of over 42,000 publications in engineering education between 1990 and 2007, approximately $0.2 \%$ investigate 
affective factors as a central component of a research investigation or intervention. Most effort focuses on the cognitive process, yet emotional (affective) factors have been demonstrated to be important players and confounding factors in technical education processes including those involving teamwork, ${ }^{1,2,3}$ academic achievement, ${ }^{4}$ and grades. ${ }^{5}$ We can argue, because of the deficit of affective studies and the many inconsistencies in cognitive models used to describe student performance, retention, and persistence, that these (affective) factors readily merit more balanced investigation. Due to the lack of research on affective elements of the student experience as well as the traditional cultural emphasis on passive/content-based learning rather than process-based/student-centered learning ${ }^{6}$ in engineering academic environments, faculty are ill prepared or trained to cope with or acknowledge the influence of student emotions on their work lives and interactions, either inside or outside of the classroom. Because of the lack of formalized structure attending to student affect in faculty instructional strategy, the tendency is clearly to advocate for the faculty to develop a "thicker" skin, absorbing rather than coping with and managing the influx of emotions from students. However, conventional wisdom strongly suggests that absorbing the negative emotions that are thrown at you is not the way to commence and maintain a successful faculty career.

Although the impact of emotions in student learning outcomes has been largely ignored in science and engineering literature, the concept of emotional labor and emotion management has been explored by social theorists such as Goffman ${ }^{7,8,9}$ and Hochschild ${ }^{10,11}$ (1979). Goffman explored how individuals and groups manage their emotions in relation to the total institutions that structure their world. In other words, how we manage or present our emotions outwardly is often radically different from our internal feelings. Part of being socialized to be part of an institution is learning to express emotions in a manner that is congruent with the goals and objectives of one's institutional culture. Hochschild's exploration of the working conditions of flight attendants indicated that often there is a set of non-articulated, yet assumed rules of conduct for emotions in the public (work, school) sphere. Emotions are considered essential attributes of labor, but are often uncompensated. Goffman defined total institutions as "a place of residence and work where a large number of like-situated individuals, cut off from the wider society for an appreciable period of time, together lead an enclosed, formally administered round of life." 12 Thus as academia is a total institution, many of the expectations of the personal and professional conduct around emotions (by faculty and students) are never formally addressed. There are gender aspects to emotional labor which have an impact on faculty experiences. Secondly, as educational paradigms (such as critical and feminist pedagogical practices) gain wider acceptance throughout the university community, emotional responses are seen not as uncomfortable moments, but as potential learning opportunities. Interpretative perspectives introduce the idea that one's subjective position not only should be acknowledged in research and scholarship, but should be valued. Essentially, this work supports the ideas of teaching the entire student and being aware of the work-intensive aspect of dealing with emotions.

\section{Student Interactions}

In many teacher training courses, there is a discussion of student body language and how to tell if students in a classroom are engaged. Slouching, heads turned away, and lack of eye contact all indicate students who are not connecting with the material. In many engineering classes, however, students are dutifully copying notes from the board but may or may not be engaged 
with the material until after class is over. Once students address difficult material, often late at night and by themselves, they may experience anger and frustration. Similarly, working with difficult topics in labs, classes and study sessions can result in the same emotions. These can then be directed at the faculty member via email, in office hours, or even in the hallways. They certainly show up in teaching evaluations! Too much of these emotions on the student side and there is a risk of losing engagement with the material for the rest of the term. Too much absorption of these emotions on the faculty side and there is risk of burnout or withdrawal from beneficial interactions with students. Five strategies to productively address student emotions and keep students and faculty engaged in the learning process are described below.

\section{Approach I: Break it up}

A student walks into your office, obviously emotional, but immediately wants help with a problem they just don't get. They've been working on it for 8 hours and have no more time and they want the answer right away. [It may be frustrating for you if there were office hours or tutors available during that period.] Rather than starting right in with an explanation that their emotional state will make difficult to follow, you can acknowledge the feelings the student is experiencing and let them move through the feelings to, hopefully, a calmness that will allow learning. Simply asking about it, "So, this is pretty frustrating?", can be enough of an acknowledgment. You can also ask the student how they are dealing with the feelings, whether they were able to focus on something else, and move on to how they approached the problem, preferably in a general sense so that it can become a discussion of strategies rather than solving a particular problem. After addressing the aspect of the student that is most in crisis, a discussion of the particular issue will be feasible and more likely to have a lasting impact.

Students are often so involved in the experience of their emotion, the difficulty and the pain, that they cannot productively focus on their work. In office hours or tutoring sessions, breaking the mental cycle of "I can't do this" or "I hate this", which begins to feel very physical, can help the student regain focus on the mental work at hand. Most of the ways to do this involve having the student reconnect with their body by intentionally moving or breathing (supported by ideas related to the mind-body problem addressed in philosophy and cognitive science). Similarly, in a class that is reaching the doldrums, having the class move, either purposefully or not, can help restore energy and focus to the class. Sometimes, this can be hidden in the action of the class by having students team up with students from the other side of the room in order to do think-pairshare or solve a small problem that illustrates the current material. Another way would be to incorporate a kinesthetic learning activity in the class where students physically act out some

aspect of the course content. ${ }^{13,14}$ It is also possible to simply have students stand up, turn around, move their arms, perhaps touch their toes. Reminding students in lab or problem solving setting to take a breath, or look away from a computer to return to their original plan, can help them practice the skills for use when they are studying on their own or taking an exam.

\section{Approach II: Make the Process Transparent}

The root of much frustration is both difficult content and new learning methods. Often the very collaborative or active learning that is shown in research to result in better retention and learning is unfamiliar and disconcerting to students. Even after many years of advocacy for active 
learning in college classrooms, it is often the students who would prefer the status quo of inactive learning. Explaining the process to students can help them deal with the difficulties because they know the purpose and can see the potential end goal.

For example, after helping students figure out a problem early in the semester, a professor can explain what was different about how she helped the students. Did you notice that I only wrote down something after you suggested it? Did you notice that I did not just tell you the answer? Do you feel like you understand it now? Is this different from what you are used to? Another example involves explicitly explaining to students, either in class or in email or other writing, the reasons for using different pedagogies and the ultimate goals. When the goal is to develop students who are life-long learners, introducing the idea of a learning process that they are a part of can benefit the student in the short and long term.

\section{Approach III: Include the Students}

Teachers can expose the potential for frustration and annoyance with the work early on, even in the first day or week of class. A class as a whole can brainstorm ways to deal with frustration. In one class, students independently came up with a list of ideas, placed in the fronts of their notebooks, which could be used when they were away from the help of tutors or the professor. Sample actions included: take a break, try a different problem, ask for help, take a deep breath, go for a walk, call a friend, look at past solutions, check the book. (They also included less productive things like "get a beer" but it is an action students do take, perhaps as a reasonable subset of "take a break".)

While "ask for help" seems like an obvious action, the authors have seen from personal experience how difficult it is for many students to ask for help. The goal of "doing it by myself" is overriding for some students and can result in students spending excess time in a frustrating cycle of not quite getting something to work, or not quite solving a problem for many more hours than today's students have. General responses to aid students who find it hard to ask for help are to make help available in less formal ways such as faculty office hours in a computer center or tutoring area, more student tutor hours (at hours students are awake), and explicit electronic office hours and electronic discussion forums.

Another difficulty for some students is that asking for help is often accompanied by fear-fear that someone in power will find out ignorance or stupidity, fear that they will never get it done or never understand it, fear that help might not be freely given. These fears can be crippling for students and make the act of going to a professor's office and asking a question seem like a large hurdle. Fears can be compounded when the lack of understanding feels so complete that words cannot be found to ask a decent question. It is one thing to say "please help me on this", it is another to express exactly where and how your understanding has broken down. One response is to help struggling students to form their questions by asking them leading questions about their understanding. This is not going to be fruitful in front of a class so there is still the problem of having enough contact with students to see their difficulties and be in a place where interaction can be helpful. If a class includes lab time, this is one opportunity. Office hours are another, but require that the student take the initiative to show up. Setting up small group problem solving in 
classes, for example, may give faculty an opportunity to help students form questions by modeling learning approaches in a smaller, safer-to-fail setting.

As students are expected to learn more complex ideas, where understanding is rarely possible in one 50-minute class period, they are going to find themselves having to sit with the feeling of "not-getting-it" for longer periods of time as they gather more information or work through problem solving. This is not a comfortable feeling and can lead to annoyance, frustration and anger. For some students, this frustration will be motivating and will result in more diligent work. For others, they will assume that this is not the field for them or that the teacher is a bad teacher and disengage from the course. By discussing expectations of when students will "get it", i.e., not today, possibly not until the end of the homework assignment, possibly not for a week, etc., faculty can help students develop the ability to sit with the frustration of not understanding everything immediately. With the expectation that our students become life-long learners, developing the skills to deal with new, difficult-to-grasp ideas is an important part of student learning. These skills are not always about having the perfect algorithm for tackling a new problem; they are also about having the emotional fortitude to bear with difficult problems and the willingness to seek help when learning approaches you have are not working.

\section{Approach IV: Share the Joy}

While much of this paper deals with negative emotions, it is important to take advantage of the positive experiences and emotions that students have in their academic careers. When students are in the throes of happiness, sharing that with them can help build connections that support learning, advising and better communication between faculty and students. Whether the joy is in solving a problem, learning a concept or something completely unrelated to the topic at hand (or to the academic side of college), sharing it can be used as positive feedback for learning and for interacting with their teachers. Welcoming their stories of extracurricular events or their lives outside of class can reduce some of the fear of asking for help discussed earlier. Similarly, the sharing of positive emotions as well as supporting students during difficult times will help build the basis of a community that includes these students as future colleagues. These connections can be useful for retention of students as well by building a positive picture of what an engineering or computer science professional looks like. Who would want to start a career that would result in a mirthless life? While this may sound like hyperbole, faculty are often the first examples of professionals in the field. Modeling enthusiasm for and engagement in life, your career, and your chosen profession for students can be very beneficial.

Listening to students, hearing their stories, sharing their joy, dealing with their emotions might feel like weighty additions to all of the other faculty tasks we have. However, the benefits of these activities are worthwhile and, as with any activity, boundaries can be set. Using the minutes before or after classes for brief interactions or inviting students to stop by your office during less busy times of the term or attending student society meetings can allow for this without a significant additional burden on your time. 


\section{Approach V: Build a Network}

It is not always possible to build a thicker skin, but you can build a support network. Acknowledging that students are learning how to cope with their emotions and knowing that the person who assigns the work or presents the difficult material is simply a convenient target can help reduce the feeling of being attacked when you are the target. Additionally, developing a faculty peer group ${ }^{15}$ or other mentor relationships can help as well. Taking advantage of workshops on student interaction or campus offerings of stress-reduction activities have the double benefits of helping acquire information or dissipating stress and increasing the possibilities of meeting potential mentors and friends who can be supportive. Most faculty members have a long history of dealing with academic frustration and difficulties with learning new problems. However, the activities that can reduce frustration for students will also help their teachers who have a little more freedom to change tasks and make choices: take a walk, learn a different thing, enjoy some deep breaths, take a yoga class, call a friend. Not only will developing a network help the teacher, it can also help students by building awareness of available services on campus such as student workshops to deal with test anxiety or other student support options.

\section{Summary}

Useful strategies for new faculty include breaking up the stress points by acknowledging emotions, making the sometimes frustrating learning process transparent, including students in the development of strategies, sharing positive emotions to build rapport, and building a network that can help reduce the need for a thicker skin. Remembering that our students have lives outside of our classes, which affect how they feel on a daily basis, can also help us deflect rather than absorb whatever gets tossed at us. Emotions are a normal by-product of the process of learning and, while they may be directed at us, they are something for students to learn to control and process rather than for us to take on. Strategies that acknowledge emotions can help students in this learning and may reduce the impact of the barrage of emotions on a professor.

\section{Acknowledgments}

The authors thank Cheryl Radeloff for her contributions on social theory and Sarah Petersen and Brad Garner for their feedback and insight.

\section{Bibliography}

\footnotetext{
${ }^{1}$ Noguez, J., Espinosa, E., \& Hernandez, Y. (2006). Work in Progress: affective models for collaborative learning, Frontiers in Education Conference: San Diego, California.

${ }^{2}$ McKinney, D. \& Denton, L.F. (2005). Affective assessment of team skills in agile CS1 labs: the good, the bad, and the ugly. SIGCSE Bulletin, vol. 37, no. 1, March 2005, pp. 465-469.

${ }^{3}$ Hansen, Stuart \& Eddy, Erica (2007). Engagement and frustration in programming projects. SIGCSE Bulletin, vol. 39, no. 1, March 2007, pp. 271-275.
} 
${ }^{4}$ Gungor, Almer, Eryilmaz, Ali, \& Fakioglu, Turgut (2007). The relationship of freshmen's physics achievement and their related affective characteristics. Journal of Research in Science Teaching, vol. 44, no. 8, pp. 1036-1056.

${ }^{5}$ Denton, Leo F. \& McKinney, Dawn (2004). Affective factors and student achievement: A quantitative and qualitative study. Frontiers in Education Conference: Savannah, Georgia.

${ }^{6}$ Felder, Richard M \& Brent Rebecca (2005). Understanding student differences. Journal of Engineering Education, vol 94, no. 1, pp. 57-72.

${ }^{7}$ Goffman, Erving (1959). The Presentation of Self in Everyday Life. Garden City, NY: Doubleday Anchor.

${ }^{8}$ Goffman, Erving (1961). Asylums. Garden City, NY: Doubleday.

${ }^{9}$ Goffman, Erving (1967). On face-work. In Interaction Ritual: Essays on Face-to-Face Behavior. Garden City, NY: Doubleday. 5-45.

${ }^{10}$ Hochschild, Arlie Russell (1979). Emotion work, feeling rules, and social structure. American Journal of Sociology, vol. 85, pp. 551-575.

${ }^{11}$ Hochschild, Arlie Russell (1983). The Managed Heart: The Commercialization of Human Feeling. Berkeley: University of California Press.

${ }^{12}$ Goffman, Erving (1961). Asylums: Essays on the Social Situation of Mental Patients and other Inmates. NY: Anchor Books.

${ }^{13}$ Begel, Andrew, Garcia, Daniel, \& Wolfman, Steven (2004). Kinesthetic learing in the classroom. SIGCSE Bulletin, vol 36, no 1, March 2004, pp. 183-184.

${ }^{14}$ Wolfman, Steven \& Bates, Rebecca (2005). Kinesthetic learning in the classroom. Journal of Computing Sciences in Colleges, vol. 21, no. 1, pp. 203-206.

${ }^{15}$ Bates, Rebecca (2005). Constructing an interdisciplinary peer mentoring network for first year faculty. American Society for Engineering Education Annual Conference \& Exposition: Portland, Oregon. 